\title{
Review \\ PI3Kinase Inhibition in Hormone Receptor-Positive Breast Cancer
}

\author{
Ajay Dhakal ${ }^{1}$, Luna Acharya ${ }^{2} \mathbb{(}$, Ruth $\mathrm{O}^{\prime}$ Regan $^{3}$, Shipra Gandhi ${ }^{4}\left(\mathbb{D}\right.$ and Carla Falkson ${ }^{1, *}$ \\ 1 Wilmot Cancer Institute, University of Rochester Medical Center, Rochester, NY 14642, USA; \\ ajay_dhakal@urmc.rochester.edu \\ 2 Department of Internal Medicine, University of Iowa Hospitals and Clinics, Iowa City, IA 52242, USA; \\ drlunaacharya@gmail.com \\ 3 Department of Medicine, University of Rochester Medical Center, Rochester, NY 14642, USA; \\ Ruth_ORegan@URMC.Rochester.edu \\ 4 Roswell Park Cancer Institute, Buffalo, NY 14203, USA; Shipra.Gandhi@RoswellPark.org \\ * Correspondence: Carla_Falkson@URMC.Rochester.edu
}

Citation: Dhakal, A.; Acharya, L.; O’Regan, R.; Gandhi, S.; Falkson, C. PI3Kinase Inhibition in Hormone Receptor-Positive Breast Cancer. Int J. Mol. Sci. 2021, 22, 11878. https:// doi.org/10.3390/ijms222111878

Academic Editor: Dario Marchetti

Received: 21 September 2021

Accepted: 29 October 2021

Published: 2 November 2021

Publisher's Note: MDPI stays neutral with regard to jurisdictional claims in published maps and institutional affiliations.

Copyright: (c) 2021 by the authors. Licensee MDPI, Basel, Switzerland. This article is an open access article distributed under the terms and conditions of the Creative Commons Attribution (CC BY) license (https:// creativecommons.org/licenses/by/ $4.0 /)$.

\begin{abstract}
Derangement of the phosphatidylinositol-3 kinase (PI3K) pathway is implicated in several subtypes of breast cancers. Mutation or upregulation of PI3K enhances cancer cells' survival, proliferation, and ability to metastasize, making it an attractive molecular target for systemic therapy. PI3K has four isoforms, and several drugs targeting individual isoforms or pan-PI3K have been or are currently being investigated in clinical trials. However, the search for an effective PI3K inhibitor with a robust therapeutic effect and reasonable safety profile for breast cancer treatment remains elusive. This review focuses on the recently completed and ongoing clinical trials involving PI3K inhibitors as mono- or combination therapy in breast cancer. We review the salient findings of clinical trials, the therapeutic efficacy of PI3K inhibitors, and reported adverse effects leading to treatment discontinuation. Lastly, we discuss the challenges and potential opportunities associated with adopting PI3K inhibitors in the clinic.
\end{abstract}

Keywords: PI3Kinase inhibitor; hormone receptor positive breast cancer; breast cancer

\section{Role and Discovery of PI3Kinase in Cancer}

Phosphatidylinositol 3 kinases (PI3Ks) are a family of intracellular lipid kinases that phosphorylate the $3^{\prime}$-hydroxyl group of lipids $\left(\mathrm{PIP}_{2}\right)$ to Phosphatidylinositol 4,5trisphosphate $\left(\mathrm{PIP}_{3}\right)$, and translate extracellular signals into cellular growth, proliferation, survival, cytoskeletal reorganization, membrane trafficking, and metabolism [1-4]. A variety of intracellular proteins can bind to the lipid products of PI3Ks in eukaryotic cells regulating a wide variety of cellular functions. PI3Ks are implicated in regulating cellular responses to multiple extracellular signals such as growth factors and insulin.

PI3Ks are divided into three classes based on their structures and substrates. Class I PI3Ks are further classified into subclasses IA and IB. Class IA PI3Ks are heterodimers including p110 catalytic and p85 regulatory units [5]. PIK3CA, PIK3CB, and PIK3CD genes express catalytic isoforms: $\mathrm{p} 110 \alpha, \mathrm{p} 110 \beta$, and $\mathrm{p} 110 \delta$, respectively. Class IB PI3Ks are heterodimers consisting of p110 $\gamma$ expressed by PIK3CG with regulatory isoforms- p101 or p87. In the absence of activating signals, p85 interacts with p110 and inhibits the PI3K activity. Following the receptor tyrosine kinase or a $\mathrm{G}$ protein receptor coupled activation, class I PI3Ks are recruited to the cell membrane, p85 inhibition is relieved, and p110 phosphorylates phosphatidylinositides. P110 $\delta$ and p110 $\gamma$ are expressed in leukocytes, while the other two isoforms are ubiquitously expressed. Class II PI3Ks are monomers and lack regulatory units. Three isoforms- PI3K-C $2 \alpha$ and PI3K-C $2 \beta$ (are ubiquitous) and PI3K$\mathrm{C} 2 \gamma$ (expressed in breast, liver, and prostate tissue) are expressed by PIK3C2A, PIK3C2B, and PIK3C2G, respectively. Class III PI3K is a heterodimer of VPS34 encoded by PIK3C3 
and a membrane-associated regulatory VPS15 protein. VPS34 is ubiquitously expressed and has a role in intercellular trafficking and autophagy.

Aberrations in the PI3K pathway are a common occurrence in human cancers [1]. The common mechanisms leading to aberrant PI3K signaling include somatic loss of Phosphatase and tensin homolog (PTEN) via genetic or epigenetic alterations, activation of receptor tyrosine kinases, or alteration in various isoforms of PI3K [1,6,7]. PIK3CA mutations are the most frequent among all isoforms in cancer. Mutations in other class I catalytic isoforms are rare in cancers. Some evidence suggests class II PI3K isoform alterations are associated with cancer [1]. There is very little evidence suggesting any oncogenic role of alterations in class III isoforms in cancer types. Upregulation of receptor tyrosine kinases, oncogenic RAS mutations, or activating p $110 \alpha$ mutations increase phosphatidylinositide (3-5) triphosphate production through p110 $\alpha$. As the pTEN enzyme inhibits this phosphorylation process, a mutation or loss of pTEN increases phosphatidylinositide (3-5) triphosphate [8]. Even in the absence of other oncogenic mutations, loss of pTEN function can increase phosphatidylinositide (3-5) triphosphate production by p110 $\beta$ activity. Activating immune cell surface markers or cytokine receptors leads to increased phosphatidylinositide (3-5) triphosphate production via p1108. Moreover, an increase in phosphatidylinositide (3-5) triphosphate causes activation of downstream Akt/mTOR pathway leading to cell growth, proliferation, and angiogenesis.

\section{PI3K in Breast Cancer}

Various genetic alterations of PI3K are associated with breast cancers. PIK3CA mutation has been reported in 7.1 to $35.5 \%$ of all breast cancers, while up to $13 \%$ of breast cancers may have copy number gain in this gene. Almost two-thirds of breast cancer show decreased expression of PIK3R1, which encodes for p85 $\alpha$, while increased expression of PIK3R2, which encodes for $\mathrm{p} 85 \beta$, is seen in $45 \%$ of breast cancers. In addition, about three-quarters of breast cancers have an increased expression of PIK3CG, which encodes for $\mathrm{p} 110 \gamma$. Isakoff et al. examined phenotypic effects of the two most common PIK3CA mutation variants- E545K and H1047R in MCF-10A immortalized breast cancer epithelial cell lines [9]. Compared to wild-type p110 $\alpha$, both mutants showed higher activity of PI3K, as well as multiple phenotypic alterations characteristic to breast tumor cells, including anchorage-independent proliferation in soft agar, growth factor independent proliferation, and protection from anoikis. In addition, mutant cell lines showed resistance to paclitaxel but sensitivity to PI3K inhibition. Similarly, Zhao et al. compared the biochemical activity and transforming potential of mutant forms of $\mathrm{p} 110 \alpha$ and $\mathrm{p} 110 \beta$ in a human mammary epithelial cell system [10]. Genetically engineered human mammary epithelial cells expressing alleles of $\mathrm{p} 110 \alpha$ - E545K and H1047R activated PI3K signaling and grew efficiently in soft agar and as orthotopic tumors in nude mice. These studies show the pathologic nature of PIK3CA mutations in breast cancer and support inhibition of the PI3K pathway as a potential therapeutic target in breast cancer (Figure 1).

Going beyond the two most common mutations E545K and H1047R of P110 $\alpha$, Zhang et al. analyzed and compared nine different PIK3CA somatic mutations using a novel cell model utilizing a lentivirus system to express different PIK3CA genes based on the human mammary epithelial cell MCF10A [11]. The phenotype of Q60K, K111N, N345K, C420R, P539R, E542K, E545K, H701P, and H1047R mutant cell lines were compared with that of p110 $\alpha$ wild type. The results showed that different PIK3CA mutants harbor varying degrees of abilities to promote cell proliferation and epidermal growth factor (EGF) independent growth. Most of these mutants were able to activate p-AKT and p-p70-S6k in the absence of EGF stimulation. Additionally, a PI3K inhibitor was able to inhibit cell growth in these PIK3CA mutant cell lines. Next, Stemke-Hale et al., 2008 performed an integrative genomic and proteomic analysis of PIK3CA, PTEN, and AKT mutations in 547 human breast tumor samples by applying mass spectroscopy-based sequencing and reverse-phase protein arrays [12]. PIK3CA mutations were seen in 34.5\% hormone receptor-positive (HR+), 22.7\% in HER2 positive (HER2+), and $8.3 \%$ in basal-like breast tumors. One point four percentage 
AKT1 mutation and 2.3\% PTEN mutations were limited to HR+ breast tumors. PTEN loss was frequently concordant with PIK3CA mutation. In 157 patients with early stage HR+ breast tumors treated with tamoxifen in the adjuvant setting, PIK3CA mutation status was not associated with outcomes. This study showed that the incidence of alterations in the PI3K pathway varies based on breast cancer subtypes, suggesting a distinct role in the pathogenesis of different breast cancer subtypes.

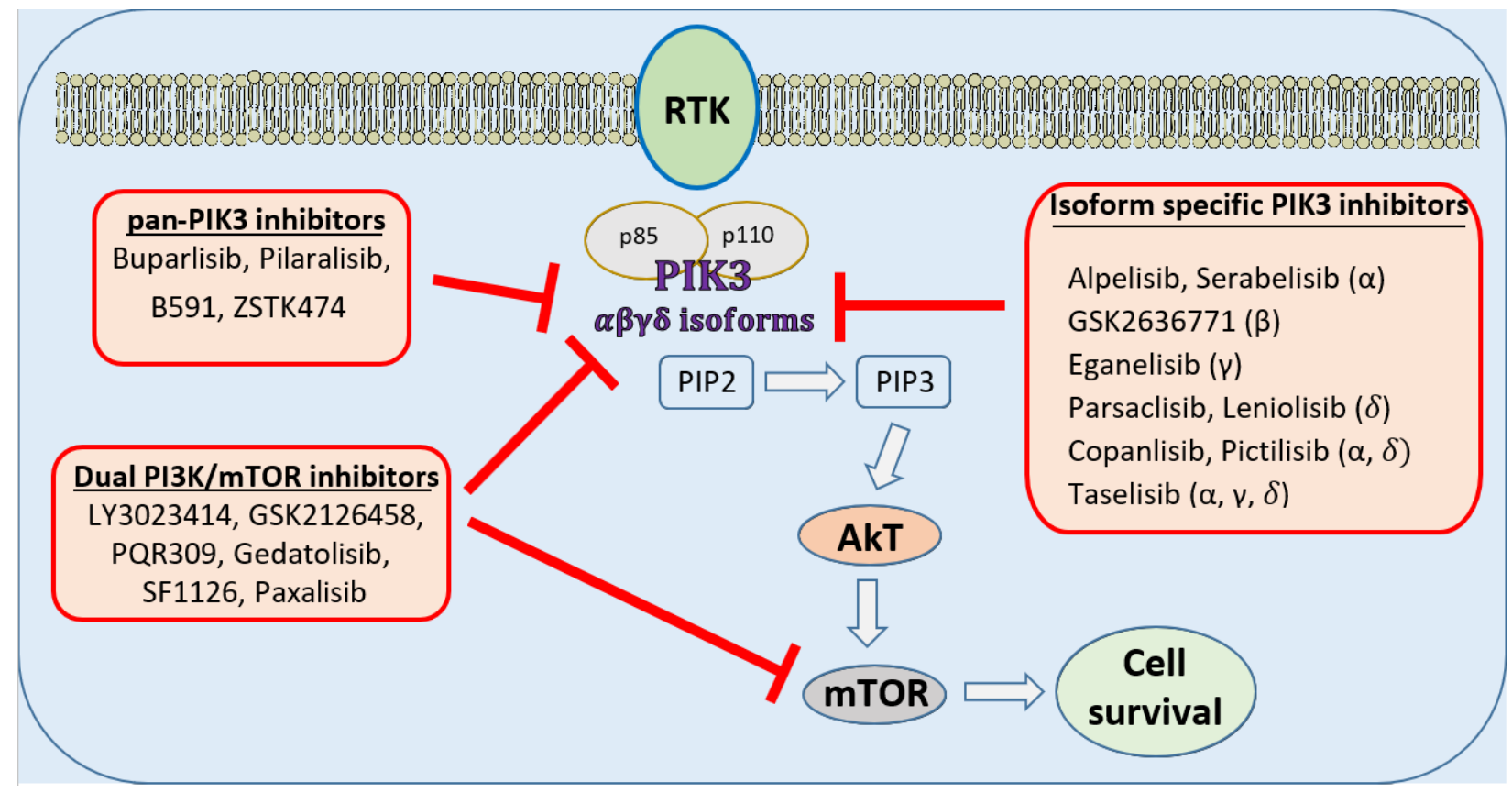

Figure 1. Molecular targets of PI3K inhibitors in the treatment of breast cancers. Activation of PI3K pathways leads to survival and proliferation of tumor cells. Multiple drugs are in clinical trials for global or isoform-specific inhibition of PI3K along with mTOR inhibition to prevent tumor cell survival and growth.

Crowder et al. examined relationships between pharmacologic inhibition and somatic mutations in PI3K catalytic subunits in HR+ breast cancer using RNA interference and PI3K catalytic subunit inhibitor BEZ235 [6]. p110 $\alpha$ RNAi inhibited growth and promoted apoptosis in all tested estrogen receptor positive $(E R+)$ breast cancer cells under estrogen-deprived conditions, whereas p110 $\beta$ RNAi only affected cells harboring PIK3CB amplification. Dual $\mathrm{p} 110 \alpha / \mathrm{p} 110 \beta$ inhibition potentiated these effects. Treatment with BEZ235, a PI3K and mammalian target of rapamycin (mTOR) inhibitor, promoted apoptosis in ER+ breast cancer cells. Estradiol suppressed these effects of gene knockouts or BEZ235. This study demonstrated synthetic lethality of $\mathrm{HR}+$ breast cancer cells with a combined inhibition of ER and PI3K. Following up on this study, Sanchez et al. attempted to identify effective PI3K pathway inhibitors and endocrine therapy combinations [7]. The PI3K catalytic subunit inhibitor BKM120, the mTOR inhibitor RAD001, and the dual PI3K/mTOR inhibitor BGT226 were tested against ER+ breast cancer cell lines before and following long-term estrogen deprivation (LTED). Drug-induced apoptosis was most marked in short-term estrogen-deprived cells with PIK3CA mutation and PTEN loss. Apoptosis was most highly induced by BGT226, followed by BKM120, and then RAD001. Estradiol was able to suppress PI3K inhibitor-induced apoptosis following short-term estrogen deprivation. These results suggested the potential clinical utility of PI3K pathway inhibition in combination with an aromatase inhibitor (AI) in de novo metastatic settings, where cancer cells have not been exposed to prolonged estrogen deprivation. Sanchez et al. also showed that LTED cells which have maintained ER expression were resistant to PI3K pathway inhibition [7]. This resistance was overcome by combining PI3K pathway inhibition with fulvestrant, a selective ER degrader. LTED cells that have lost ER expression demonstrated sensitivity to 
PI3K pathway inhibition as a single agent. These results support the clinical utility of PI3K pathway inhibition in combination with fulvestrant to treat breast cancers with prolonged estrogen deprivation, such as ER+ breast cancers that recur after adjuvant $\mathrm{AI}$ or metastatic $\mathrm{ER}+$ breast cancer that progresses on AI therapy.

Currently, multiple pharmaceutical companies are investigating pan PI3K, isoformspecific PI3K, and dual mTOR/PI3K inhibitors in clinical trials for treating breast cancer, as depicted in Figure 1 [1]. In Table 1 we have described some of the recently completed clinical trials involving PI3K inhibitors in the management of breast cancer. These clinical trials were searched in the online database of www.clinicaltrials.gov, last accessed on 1 September 2021.

Table 1. Recently completed clinical trials involving PI3K inhibition as a therapeutic agent against HR+, HER2+, and triple-negative breast cancers.

\begin{tabular}{|c|c|c|c|c|}
\hline $\begin{array}{c}\text { Trial ID and Year } \\
\text { of Publication }\end{array}$ & Pharmacological Agents & Cohort and Settings & Clinical Outcome & Key Adverse Effects \\
\hline \multicolumn{5}{|c|}{ HER2+ Breast Cancer } \\
\hline $\begin{array}{c}\text { NCT01816594 } \\
\text { (NeoPHOEBE), } 2017 \text { [13] }\end{array}$ & $\begin{array}{l}\text { Trastuzumab +Paclitaxel } \\
\text { with buparlisib/placebo }\end{array}$ & $\begin{array}{l}\text { HER2+ breast cancer, } \\
\text { randomized phase } \\
\text { II, neoadjuvant }\end{array}$ & $\begin{array}{l}\text { Trial suspended mainly } \\
\text { due to liver toxicity }\end{array}$ & $\begin{array}{l}\text { Liver dysfunction, } \\
\text { diarrhea, alopecia, early } \\
\text { fatigue, skin rash }\end{array}$ \\
\hline NCT02390427, 2017, [14] & Taselisib + TDM1 & $\begin{array}{c}\text { Metastatic HER } 2+\text { breast } \\
\text { cancer who have received } \\
\text { prior treatments for } \\
\text { metastatic breast cancer, } \\
\text { Phase I }\end{array}$ & $\begin{array}{l}\text { Median progression-free } \\
\text { survival (PFS) } 7.6 \text { months }\end{array}$ & $\begin{array}{l}\text { Diarrhea, vomiting, } \\
\text { pneumonitis, } \\
\text { thrombocytopenia }\end{array}$ \\
\hline NCT02038010, 2018, [15] & Alpelisib + TDM1 & $\begin{array}{l}\text { HER2+ metastatic breast } \\
\text { cancer, which has } \\
\text { progressed on } \\
\text { trastuzumab, Phase I }\end{array}$ & $\begin{array}{l}\text { Median PFS } 8.1 \text { months, } \\
\text { Maximum tolerated dose } \\
\text { of Alpelisisb } 250 \mathrm{mg} \text { daily }\end{array}$ & $\begin{array}{l}\text { Easy fatigue, weight loss, } \\
\text { hyperglycemia, } \\
\text { hypertension, pancreatitis. }\end{array}$ \\
\hline \multicolumn{5}{|c|}{ HR+ Breast Cancer } \\
\hline NCT01219699, 2019, [16] & Alpelisib and Fulvestrant & $\begin{array}{l}\text { HR+ advanced breast } \\
\text { cancer, phase } \mathrm{Ib}\end{array}$ & $\begin{array}{l}\text { Significant clinical activity } \\
\text { and reasonable safety } \\
\text { profile; recommended } \\
\text { phase II dose of alpelisib } \\
300 \mathrm{mg} \text { daily }\end{array}$ & $\begin{array}{l}\text { Easy fatigue, vomiting, } \\
\text { diarrhea, hyperglycemia, } \\
\text { skin rash. }\end{array}$ \\
\hline $\begin{array}{c}\text { NCT02437318 (SOLAR 1), } \\
\text { 2021, [17] }\end{array}$ & Alpelisib and Fulvestrant & $\begin{array}{l}\text { PIK3CA-mutated HR+ } \\
\text { advanced breast cancer }\end{array}$ & $\begin{array}{l}\text { Numerical improvement } \\
\text { of } 7.9 \text { months in median } \\
\text { overall survival } \\
\text { with alpelisib }\end{array}$ & $\begin{array}{l}\text { Hyperglycemia, skin } \\
\text { rash, diarrhea }\end{array}$ \\
\hline $\begin{array}{c}\text { NCT02273973 (LORELEI), } \\
\text { 2019, [18] }\end{array}$ & Taselisib and Letrozole & $\begin{array}{c}\text { HR+, HER2 negative early } \\
\text { stage breast cancer } \\
\text { in neoadjuvant } \\
\text { settings, randomized } \\
\text { phase II study }\end{array}$ & $\begin{array}{l}\text { Increased objective } \\
\text { response with the addition } \\
\text { of taselisib. }\end{array}$ & $\begin{array}{l}\text { Easy fatigue, diarrhea, } \\
\text { hyperglycemia, skin } \\
\text { rash, arthralgia. }\end{array}$ \\
\hline \multicolumn{5}{|c|}{ Triple Negative Breast Cancer } \\
\hline NCT01790932, 2020 [19] & Buparlisib & $\begin{array}{l}\text { Triple-negative metastatic } \\
\text { breast cancer, single-arm } \\
\text { phase II study }\end{array}$ & $\begin{array}{c}\text { clinical benefit rate } \\
\text { of only } 12 \%\end{array}$ & $\begin{array}{l}\text { Fatigue, nausea, } \\
\text { anorexia, hyperglycemia }\end{array}$ \\
\hline \multicolumn{5}{|c|}{ HER2 Negative Breast Cancer } \\
\hline NCT02457910, 2020, [20] & $\begin{array}{l}\text { Taselisib plus } \\
\text { anti-androgen therapy } \\
\text { Enzalutamide }\end{array}$ & $\begin{array}{c}\text { Androgen Receptor }(\mathrm{AR})+, \\
\text { metastatic breast cancer, } \\
\text { phase } \mathrm{Ib} / \mathrm{II}\end{array}$ & $\begin{array}{l}\text { An increase in clinical } \\
\text { benefit rate with the } \\
\text { combination among } \\
\text { AR+ TNBC }\end{array}$ & $\begin{array}{l}\text { Hyperglycemia, } \\
\text { skin rash, fever, easy } \\
\text { fatigue, vomiting }\end{array}$ \\
\hline $\begin{array}{l}\text { NCT01572727 (BELLE 4), } \\
\text { 2017, [21] }\end{array}$ & $\begin{array}{l}\text { Paclitaxel with } \\
\text { Buparlisib/placebo }\end{array}$ & $\begin{array}{l}\text { HER2 negative locally } \\
\text { advanced or metastatic } \\
\text { breast cancer (MBC) with } \\
\text { no prior chemotherapy for } \\
\text { MBC; Phase II/III }\end{array}$ & $\begin{array}{l}\text { Suspended after Phase II } \\
\text { due to futility }\end{array}$ & $\begin{array}{l}\text { Diarrhea, alopecia, } \\
\text { skin rash, nausea, } \\
\text { hyperglycemia, } \\
\text { reduced appetite. }\end{array}$ \\
\hline
\end{tabular}

\section{Buparlisib (BKM120)}

BKM120 was identified as a potent pan-class I PI3K inhibitor (targeting all four isoforms- $\alpha$, $\beta, \gamma, \delta)$ among a series of substituted 6-amino heterocyclic, 2,4-bismorpholinopyrimidines [22]. 
The lack of isoform specificity increases the toxicity of buparlisib in a dose-dependent manner. Two separate first-in-human phase I studies among patients with advanced solid tumors identified $100 \mathrm{mg} /$ day of buparlisib as the maximum tolerated dose [23-25]. Next, a phase Ib study evaluated buparlisib plus letrozole's safety, tolerability, and preliminary activity in patients with metastatic HR+ breast cancer refractory to endocrine therapy [26]. Fifty-one patients were evaluated on this combination, demonstrating a maximum tolerated dose (MTD) of $100 \mathrm{mg}$ for buparlisib. Common drug-related adverse events (AEs) included $\leq$ grade 2 hyperglycemia, nausea, fatigue, transaminitis, and mood disorders. At six months, the clinical benefit rate among all patients treated at the MTD was 31\%, including two objective responses. Clinical activity was independent of PIK3CA mutation status. Ma et al., 2016 conducted a study with a $3+3$ design to determine the MTD of buparlisib daily plus fulvestrant. Subsequent cohorts (phase IB and cohort C) evaluated intermittent (5/7-day) and continuous dosing of buparlisib (100 mg daily). Thirty-one patients were enrolled, and the MTD for buparlisib was $100 \mathrm{mg}$ /day in combination with fulvestrant. Common AEs included fatigue (38.7\%), transaminase elevation (35.5\%), rash $(29 \%)$, and diarrhea (19.4\%). Daily buparlisib was associated with more frequent early onset AEs and higher buparlisib plasma concentrations than intermittent dosing. Among the 29 evaluable patients, the clinical benefit rate was $58.6 \%$ (95\% CI, 40.7-74.5\%). The response was not associated with PIK3CA mutation in the treatment cohort. Based on these preliminary results, BELLE-2, a randomized, double-blind, placebo-controlled, multicenter study, evaluated the efficacy of buparlisib plus fulvestrant in patients with advanced breast cancer [27]. One thousand one hundred forty-seven patients whose breast cancer had progressed on an AI and who had received up to one previous line of chemotherapy were randomized in a 1:1 fashion to fulvestrant plus buparlisib vs. fulvestrant plus placebo. Median progression-free survival (PFS) was 6.9 months (95\% CI 6.8-7.8) in the buparlisib group versus 5.0 months (4.0-5.2) in the placebo group (hazard ratio (HR) 0.78 (95\% CI $0.67-0.89)(p<0.05)$. In patients with PI3K pathway-activated breast cancers $(n=372)$, median PFS was 6.8 months (95\% CI 4.9-7.1) in the buparlisib group versus 4.0 months (3.1-5.2) in the placebo group (HR $0.76(0.60-0.97)$, one-sided $p=0.014)$. The most common grade 3-4 (G3-4) adverse events in the buparlisib group versus the placebo group were increased alanine aminotransferase (146 (25\%) of 573 patients vs. six ( $1 \%)$ of 570$)$, increased aspartate aminotransferase (103 (18\%) vs. $16(3 \%))$, hyperglycemia (88 $(15 \%)$ vs. one $(<1 \%))$, and rash $(45(8 \%)$ vs. none). Serious adverse events were reported in $134(23 \%)$ of 573 patients in the buparlisib group compared with $90(16 \%)$ of 570 patients in the placebo group. This trial showed that PI3K pathway inhibition was effective in combination with endocrine therapy in advanced HR+ metastatic breast cancer $(\mathrm{MBC})$, but more selective PI3K inhibitors were needed to improve safety. Similarly, BELLE-3, a randomized, doubleblind, placebo-controlled, multicenter, phase III study, evaluated the safety and efficacy of buparlisib plus fulvestrant in patients with advanced HR+ HER2 negative (HER2-) breast cancer who were pretreated with endocrine therapy and mTOR inhibition [28]. Four hundred thirty-two patients were randomly assigned (2:1) to buparlisib vs. placebo arm. Median PFS was significantly longer in the buparlisib vs. placebo group (3.9 months (95\% CI 2.8-4.2) vs. 1.8 months (1.5-2.8); hazard ratio $0.67,95 \%$ CI $0.53-0.84$, one-sided $p=0.00030$ ). The most frequent grade $3-4$ adverse events in the buparlisib versus placebo group were elevated alanine aminotransferase (63 (22\%) of 288 patients vs. four ( $3 \%)$ of 140$)$, elevated aspartate aminotransferase $(51(18 \%)$ vs. four $(3 \%))$, hyperglycemia (35 (12\%) vs. none). The safety signals from BELLE-2 and BELLE-3 did not support further development of buparlisib in the setting of metastatic HR+ BC. A phase IB study investigated the effects of buparlisib in combination with tamoxifen and goserelin on HR+, HER2- advanced breast cancer. The study enrolled pre-menopausal women and primarily tested the safety profile of buparlisib. No unexpected safety signals were reported. However, the high occurrence of treatment-emergent side effects led to treatment discontinuation in $53.8 \%$ of the patients [29]. Another recently concluded phase $\mathrm{Ib}$ trial investigated the therapeutic potential of buparlisib or alpelisib with ribociclib and fulvestrant in HR+ advanced breast 
cancer. Patient recruitment for this triple combination cohort in the study was stopped due to unexpected toxicity. The use of buparlisib or alpelisib in combination with ribociclib and fulvestrant was not recommended in further phase II clinical trials [30].

A recent phase II study of buparlisib in patients with triple-negative MBC found no objective response to the treatment. The drug downregulated the key proteins in the PI3K pathway but prevented disease progression in a tiny subset of patients. Fatigue, nausea, hyperglycemia, and anorexia were common symptoms in the patients. The investigators concluded that buparlisib alone might not be a good therapeutic option for triple-negative breast cancer [19].

\section{Taselisib (GDC-0032)}

Taselisib is a selective $\beta$ sparing PI3K inhibitor [31,32]. A preclinical study evaluated taselisib as a single agent and in combination with letrozole in a breast cancer cell line engineered to express aromatase [33]. The combination of taselisib and letrozole decreased cellular viability and increased apoptosis relative to either single agent alone. Targeting the crosstalk signaling between the PI3K and ER pathways was associated with the efficacy of this combination. Multiple soluble factors, including members of the epidermal and fibroblast growth factor families, rendered breast cancer cells non-responsive to letrozole. It was discovered that many of these factors signal through the PI3K pathway, and cells remained sensitive to taselisib in the presence of the soluble factors. It was found that letrozole resistant lines have elevated PI3K pathway signaling due to an increased level of p $110 \alpha$ but are still sensitive to taselisib. This study provided a rationale for combining taselisib with endocrine therapy to overcome resistance to endocrine therapy in breast cancer. An open-label phase II study evaluated taselisib plus fulvestrant in 60 postmenopausal women with locally advanced or metastatic HR+, HER2- breast cancer. The median duration of treatment was 4.6 months. The response rates among those with and without PIK3CA mutation were 38.5\% and 14.3\%, respectively [34]. Fifty percent of patients had grade 3 or higher AEs, and $31.7 \%$ had serious AEs. The SANDPIPER study was a phase III randomized, placebo-controlled trial of taselisib plus fulvestrant compared placebo plus fulvestrant in patients with HR+ PIK3CA mutant, locally advanced, or metastatic AI-resistant breast cancer. There was a two-month improvement in median PFS in the taselisib arm as compared to the placebo arm (7.4 vs. 5.4 months, hazard ratio $0.70(0.56,0.89), p<0.05)$. The taselisib arm was associated with $49.5 \%$ grade 3 or higher AE and $32 \%$ serious AEs compared to $16.4 \%$ and $8.9 \%$, respectively, in the placebo arm. The most common G3 or higher AEs in the taselisib arm as compared to the placebo arm were diarrhea $(11.5 \%$ vs. $<1 \%)$, hyperglycemia $(10.8 \%$ vs. $<1 \%)$, rash (3.8\% vs. not reported), and stomatitis (3.6\% vs. not reported). The toxic effects led to more treatment discontinuation in the taselisib than in the placebo group $(16.8 \%$ vs. $2.3 \%)$. This result demonstrated poor tolerability of this drug with a limited clinical benefit $[35,36]$. The investigators concluded that the moderate clinical benefit and low safety profile of taselisib and fulvestrant did not warrant further investigation of this combination. In a phase $\mathrm{Ib}$ study, the safety and efficacy of triplet therapy- palbociclib plus fulvestrant and taselisib among 25 patients with HR+ HER2-, PIK3Ca mutant advanced breast cancer were investigated. The objective response rate was $30 \%$ with the triplet therapy. However, due to the single-arm nature of the study and the small sample size, further randomized larger studies are needed to establish clinical benefits. The most common grade 3/4 AEs in the overall 58 expansion-phase patients (including the triplet therapy cohort and HR+ HER2- PIK3CA unselected cohort and an ER-negative PIK3CA mutant breast cancer or other solid tumor cohort) were neutropenia (53\%) and leukopenia (21\%). The most common grade $3 / 4$ treatment-related AEs were neutropenia (53\%) and leukopenia (19\%). Overall, 30\% of patients developed serious AE in this study [37]. Interestingly, taselisib as monotherapy has limited therapeutic activity in PIK3CA breast cancer. A phase I clinical trial investigated the effects of taselisib in patients with PIK3CA mutated breast cancer and reported a very narrow therapeutic index with a response rate of $9 \%$ [38]. 


\section{Alpelisib}

Alpelisib is a selective PIK3 $\alpha$ inhibitor [39]. Inhibition of PIK3 $\alpha$ results in a reactive increase in ER-dependent transcriptional activity leading to resistance to alpelisib, indicating a concurrent blockade of ER pathway may overcome therapeutic resistance to alpelisib [40]. Preclinically, alpelisib is synergistic with fulvestrant causing significant tumor regression [40]. Following this encouraging preclinical activity, clinical trials were conducted exploring the combination of alpelisib and endocrine therapies. A phase $1 \mathrm{~b}$ study evaluated 26 patients with metastatic HR+ HER2 - breast cancer refractory to endocrine therapy for safety and tolerability of alpelisib plus letrozole [41]. Common drug-related AEs on the MTD of $300 \mathrm{mg}$ daily were hyperglycemia $(55 \%)$, nausea $(60 \%)$, fatigue $(45 \%)$, diarrhea $(80 \%)$, and rash $(45 \%)$. Clinical benefit rates in tumors with and without PIK3CA mutation were $44 \%$ and $20 \%$, respectively. Similarly, another phase $1 \mathrm{~b}$ study evaluated 87 patients with endocrine-resistant, HR+ HER2 - metastatic breast cancer for safety and activity of alpelisib plus fulvestrant [16]. The MTD of alpelisib in combination with fulvestrant was $400 \mathrm{mg}$ daily. Common AEs on $400 \mathrm{mg}$ of alpelisib were nausea (50\%), diarrhea (59\%), hyperglycemia $(49 \%$, G3 or higher $23 \%)$, fatigue $(36 \%)$, vomiting $(33 \%)$, and decreased appetite (47\%) but most of these AEs were grade 2 or less. The median PFS in patients with and without PIK3CA mutant tumors was 9.1 (6.6-14.6) months vs. 4.7 (1.9-5.6) months. Alpelisib $300 \mathrm{mg}$ daily was selected as the recommended phase 2 dose for future studies because of the similar clinical activity of alpelisib across various dose levels and fewer dose modifications. The phase III placebo-controlled SOLAR- 1 trial randomized 572 patients with endocrine-resistant advanced breast cancers who had received prior AI in the neoadjuvant/adjuvant or metastatic settings, including 341 patients with PIK3CA mutation, to fulvestrant with either alpelisib or placebo. In the PIK3CA mutant cohort, median PFS was 11 (7.5-14.5) months in the alpelisib arm vs. 5.7 (95\% CI, 3.7-7.4) months in the placebo arm $(p<0.05)$ [42]. Among the PIK3CA wild type cohort, the median PFS was 7.4 months (95\% CI, 5.4 to 9.3 ) in the alpelisib arm and 5.6 months (95\% CI, 3.9 to 9.1) in the placebo arm (HR for progression or death, $0.85 ; 95 \% \mathrm{CI}, 0.58$ to 1.25 ). Seventy-six percent of patients in the alpelisib arm developed G3 or G4 AEs, while only 35.5\% of patients in the placebo arm developed similar AEs. Most common G3 or G4 AEs in alpelisib arm as compared to placebo arm were hyperglycemia ( $36 \%$ vs. $<1 \%)$, diarrhea $(6.7 \%$ vs. $<1 \%)$, and rash $(9.9 \%$ vs. $<1 \%)$. Based on the SOLAR-1 study, alpelisib, in combination with fulvestrant, was approved by FDA in 2019 to treat HR+, HER2-, PIK3CA mutated breast cancers [43]. Recently, some anecdotal evidence suggests that alpelisib has intracranial activity in patients with PIK3CA mutant HR+ HER2 - metastatic breast cancer and brain metastasis. Four cases of HR+ HER2 - breast cancers with brain metastasis were reported to be treated with an alpelisib combination resulting in a partial response (per Response Assessment in Neuro-Oncology Brain Metastasis criteria) in one of them [44]. Further anecdotal data suggesting intracranial activity of alpelisib may continue to emerge in the future as the 2019 FDA approval of this molecule will lead to an increase in its use for HR+ MBC with PIK3CA mutations. Such anecdotal data should be interpreted with caution as they are subjected to biases. Definitive genomically guided treatment trials focused on breast cancer brain metastasis may provide more definite clinical information regarding the activity and benefit of targeted drugs like alpelisib in breast cancer patients with brain metastasis. Similarly, more flexible inclusion criteria allowing more brain metastasis patients in large randomized trials of alpelisib may provide useful information regarding the intracranial activity of this molecule.

\section{Utility and Limitation of Current Alpelisib Data}

The current standard of care first-line treatment for HR+ HER2- MBC is an aromatase inhibitor combined with a CDK4/6 inhibitor (CDK4/6i). It may be reasonable to use single-agent $\mathrm{AI}$ in the first-line setting, especially for breast cancer with known endocrine sensitivity or with low tumor burden or bone-only disease. After progression on AI, these tumors can be treated with fulvestrant combined with a CDK4/6i in the second 
line. Based on the design and data from the SOLAR 1 trial, i.e., alpelisib in combination with fulvestrant provided significant PFS benefit compared to fulvestrant alone among HR+ HER2- PIK3CA mutant MBC previously treated with an AI. Therefore, alpelisib, in combination with fulvestrant, is recommended in the second line after the progression on first-line antiestrogen therapy with or without a CDK4/6i for patients with PI3K-mutant cancers. However, the SOLAR-1 study enrolled a minimal number of patients who had prior CDK4/6i as the trial's accrual was mostly before approval and widespread use of CDK4/6i. It is unclear if alpelisib and fulvestrant will have the same efficacy in tumors resistant to CDK4/6i. Similarly, for patients who have been treated with single-agent AI in the first-line setting and have PIK3CA mutant breast cancer, there is a lack of data to help choose between fulvestrant plus a CDK4/6i vs. fulvestrant plus alpelisib. Additionally, if a patient has already received a prior fulvestrant in the metastatic setting, it is unclear if alpelisib plus an endocrine partner other than fulvestrant will have meaningful clinical activity in these settings. These gaps in knowledge are being explored to some extent in the ongoing BYLieve study (NCT03056755). This is a phase II, open-label, non-comparative study to assess the efficacy and safety of alpelisib plus ET (fulvestrant or letrozole) in patients with PIK3CA-mutant, HR+, HER2 - advanced breast cancer who have progressed on or after prior treatments. There are three cohorts in this trial. Eligible patients who received $\mathrm{CDK} 4 / 6 \mathrm{i}$ plus $\mathrm{AI}$ as the immediate prior therapy are enrolled in the first cohort and receive alpelisib and fulvestrant as investigational treatment. Eligible patients who received CDK4/6i plus fulvestrant as immediate prior treatment are enrolled in the second cohort and receive alpelisib plus letrozole as investigational treatment. Patients who progressed on/after AI and received chemotherapy or ET as immediate prior treatment are enrolled in the third cohort and receive alpelisib and fulvestrant as investigational treatment. The primary endpoint is six months PFS. One hundred twenty-seven patients with PIK3CA mutant metastatic breast cancer who had received an AI plus a CDK4/6i as an immediate prior treatment were enrolled and received fulvestrant plus alpelisib. Most of the patients had received only one prior line of therapy (70\%) in the metastatic setting and had endocrine-resistant tumors (81\%). In cohort A, the six-month PFS was $50.4 \%$, and the median PFS was 7.3 months [45]. Multiple studies have shown that PIK3CA mutations are associated with poor prognosis in metastatic HR+ Breast cancer $[46,47]$. The BYLieve cohort A result has suggested a modest clinical activity of fulvestrant plus alpelisib in PIK3CA mutant breast cancer before being treated with a CDK4/6i and has provided novel prospective efficacy data of alpelisib plus fulvestrant in this space, making this combination a therapeutic option post-CDK4/6i. Similarly, preliminary results of cohort B have been presented. One hundred twenty-six patients with PIK3CA mutant metastatic HR+ breast cancer with Fulvestrant and CDK4/6i as the immediate prior therapy were enrolled in cohort B of the BYLieve study and received letrozole plus alpelisib. Forty-six percent had received two or more lines of prior therapies in the metastatic setting, suggesting a more heavily treated cohort than cohort A. After a median follow-up of 15 months, 6 months PFS was $46 \%$, median PFS was 5.7 months [48]. This is a novel prospective data of the efficacy of alpelisib in combination with fulvestrant in PIK3CA mutant HR+ metastatic breast cancer after cancer progresses on CDK4/6i plus fulvestrant. However, BYLieve generates nonrandomized single-arm data and is thus considered lower-level evidence. After the SOLAR1 results established the clinical activity of alpelisib among PIK3CA mutant HR+ HER2- MBC, randomized placebo-controlled studies to show the efficacy of alpelisib in unique cohorts not included by SOLAR-1 like post CDK4/6i or in combination with $\mathrm{AI}$ in post fulvestrant space will likely pose ethical and enrollment challenges. Randomized clinical trials comparing alpelisib combinations with other existing antiestrogen/CDK4/6i therapy options among PIK3CA mutant metastatic HR+ breast cancer are needed to understand the optimal sequence of therapy in the 1st and 2nd line therapy. Additionally, optimal sequencing strategies and efficacy of the mTOR inhibitor, everolimus, are unclear in this era of newer targeted strategies like CDK4/6i combinations 
and alpelisib plus endocrine therapy combinations in the treatment for metastatic HR+ breast cancer.

\section{Opportunity and Challenges of Adopting PI3K Inhibitors in Clinic}

Based on the results of SOLAR-1 study, alpelisib in combination with fulvestrant for postmenopausal women, and men, with HR+, HER2-, PIK3CA-mutated MBC. Alpelisib remains the only PI3K inhibitor to be approved in the management of breast cancer till date and has been adopted in the clinics due to associated benefit in progression free survival. However, alpelisib is associated with significant adverse reactions which pose challenge in its use in clinical practice. The most common side effects are hyperglycemia, diarrhea, nausea, anorexia and rash. In the SOLAR-1 trial, the discontinuation rate due to adverse reaction was $25 \%$ with alpelisib as compared to $4 \%$ with placebo. It is critical that the oncology providers are well versed with the monitoring and management of unique side effects of alpelisib like hyperglycemia and rash. Future real-world studies will help optimize the prevention and mitigation strategies of these side effects associated with alpelisib.

\section{Cross Trial Comparison of Alpelisib, Taselisib and Buparlisib}

Buparlisib, a pan PIK3 inhibitor, and taselisib, a selective $\beta$ isoform sparing PIK3 inhibitor, suffered from "off-target" effects causing a wide range of high-grade AEs across different organ systems, including GI, hepatobiliary, skin, and endocrine. Taselisib was associated with a limited improvement in median PFS among the patients with PIK3CA mutant tumor, suggesting a weak "on target" activity. Among patients with tumors resistant to endocrine therapy (BELLE2) and patients with tumors resistant to endocrine therapy and mTOR inhibition (BELLE 3), there was a lack of consistency in the benefit of buparlisib in PIK3CA mutant tumors, and overall efficacy was modest. These data with buparlisib were unable to show a precise "on target" activity against the PI3K pathway in these tumors. On the other hand, alpelisib is shown to have strong "on target" activity as demonstrated by almost doubling of median PFS among patients with PIK3CA mutation and no significant improvement associated among patients without PIK3CA mutation. Hyperglycemia is one of the "on target" activities associated with inhibition of PIK $\alpha$. Other than this, there were minimal G3 or higher AEs associated with alpelisib. So, alpelisib has been able to stand out among the PIK3 kinase inhibitors investigated in managing breast cancer due to clinically meaningful benefits at the expense of manageable AEs. Therefore, in May 2019, the FDA approved alpelisib (PIQRAY ${ }^{\circledR}$ ) in combination with fulvestrant for postmenopausal women and men with HR+ HER2- PIK3CA-mutated, advanced, or metastatic breast cancer following progression on or after an endocrine-based regimen.

\section{Future Perspectives with PI3K Inhibitors in HR+ Breast Cancer}

Several clinical trials are currently underway, testing the further therapeutic efficacy of PI3K inhibition in breast cancer. Table 2 represents a summary of the active trials involving HR+, HER2 - breast cancers. The trials are investigating various PI3K inhibitors, $\mathrm{PI} 3 \mathrm{~K} / \mathrm{mTOR}$ inhibitors, PI3K/AKT inhibitors in combination with endorine therapies or other targeted therapies like CDK4/6i to treat $\mathrm{HR}+$ breast cancer.

Table 2. The ongoing clinical trials involving PI3K inhibition as a therapeutic agent against HR+/HER2- breast cancer.

\begin{tabular}{|c|c|c|c|c|}
\hline Trial ID & Study Treatment & Phase & $\begin{array}{c}\text { Breast Cancer } \\
\text { Receptor/Mutation Type }\end{array}$ & Stage \\
\hline NCT02626507 & $\begin{array}{c}\text { Gedatolisib } \\
\text { (PI3Kinase/mTOR } \\
\text { pathway inhibitor), } \\
\text { Faslodex, Palbociclib, } \\
\text { and Zoladex }\end{array}$ & $\mathrm{Ib}$ & $\begin{array}{l}\text { HR+ HER2 negative, PIK3CA } \\
\text { mutant or wildtype }\end{array}$ & $\begin{array}{c}\text { Neoadjuvant settings } \\
\text { for untreated } \\
\text { breast cancers }\end{array}$ \\
\hline
\end{tabular}


Table 2. Cont.

\begin{tabular}{ccccc}
\hline Trial ID & Study Treatment & Phase & $\begin{array}{c}\text { Breast Cancer } \\
\text { Receptor/Mutation Type }\end{array}$ & Stage \\
\hline NCT01625286 & $\begin{array}{c}\text { AZD533 (PI3Kinase/AKT } \\
\text { pathway inhibitor) } \\
\text { and paclitaxel }\end{array}$ & I/II & $\begin{array}{c}\text { HR+ HER2 negative, PIK3CA } \\
\text { mutant or wildtype }\end{array}$ & metastatic breast cancer \\
\hline NCT02389842 & $\begin{array}{c}\text { Palbociclib and Taselisib } \\
\text { or Pictelisib }\end{array}$ & Ib & PIK3CA mutant only & advanced solid tumors \\
\hline NCT01872260 & $\begin{array}{c}\text { Ribociclib, Letrozole } \\
\text { and alpelisib }\end{array}$ & Ib & $\begin{array}{c}\text { HR+ HER2 negative } \\
\text { PIK3CA mutant or wildtype }\end{array}$ & metastatic breast cancer \\
\hline NCT04300790 & $\begin{array}{c}\text { Alpelisib, Metformin } \\
\text { and Fulvestrant }\end{array}$ & II & HR+ HER2 negative, \\
PIK3CA mutant & metastatic breast cancer \\
\hline NCT03803761 & $\begin{array}{c}\text { Copanlisib (PI3Kinase } \\
\text { inhibitor- alpha and delta) } \\
\text { and fulvestrant }\end{array}$ & II & PIK3CA mutant or PTEN loss & $\begin{array}{c}\text { Advanced metastatic } \\
\text { breast cancer }\end{array}$ \\
\hline
\end{tabular}

\section{Conclusions}

In conclusion, several PI3K inhibitors are in clinical trials to assess safety, tolerability, and efficacy for managing HR+ breast cancers. Alterations in the PI3K pathway in HR+ breast cancer are a common resistance mechanism to endocrine therapy. Alpelisib, an alpha isomer-specific PI3K inhibitor, has demonstrated efficacy and tolerability in combination with fulvestrant in patients with $\mathrm{HR}+\mathrm{MBC}$ with PIK3CA mutations who have received prior endocrine therapy. Ongoing studies will help us identify better therapeutic strategies regarding combining and sequencing PI3K inhibitors with various endocrine therapies to overcome therapeutic resistance.

Author Contributions: Study Conception and Design: A.D. and C.F.; Literature Search: A.D. and L.A.; Manuscript Preparation: A.D., L.A., R.O., S.G. and C.F. All authors have read and agreed to the published version of the manuscript.

Funding: Research reported in this publication was supported by the National Center for Advancing Translational Sciences of the National Institutes of Health under award Number KL2TR001413 and UL1TR001412. The content is solely the responsibility of the authors and does not necessarily represent the official views of the NIH.

Conflicts of Interest: A.D. has received honorarium from MJH Life sciences; L.A. and S.G. no COI; R.O. served as consultant to Immunomedics, Macrogenics, Pfizer, Genomic Health, Biotheranostics, Novartis, Lilly, Puma, Genenech; Grant research support from Novartis; C.F. honoraria from Curio Sciences, Exact Sciences and OncLive; current or prior institution of C.F. has received research funding for clinical trials for which C.F. is/has been PI: Oncolytics Biotech; QuantumLeap health, Eli Lilly; Seagen; Pfizer; Novartis and Genentech.

$\begin{array}{ll}\text { Abbreviations } \\ \text { PI3K } & \text { phosphatidylinositol-3 kinase } \\ \text { EGF } & \text { epidermal growth factor } \\ \text { HR } & \text { hormone receptor } \\ \text { ER } & \text { estrogen receptor } \\ \text { LTED } & \text { long-term estrogen deprivation } \\ \text { AI } & \text { aromatase inhibitor } \\ \text { PFS } & \text { progression free survival } \\ \text { AE } & \text { adverse event } \\ \text { G } & \text { grade } \\ \text { MBC } & \text { metastatic breast cancer } \\ \text { MTD } & \text { maximum tolerated dose }\end{array}$




\section{References}

1. Thorpe, L.M.; Yuzugullu, H.; Zhao, J.J. PI3K in cancer: Divergent roles of isoforms, modes of activation and therapeutic targeting. Nat. Rev. Cancer 2015, 15, 7-24. [CrossRef]

2. Engelman, J.A.; Luo, J.; Cantley, L.C. The evolution of phosphatidylinositol 3-kinases as regulators of growth and metabolism. Nat. Rev. Genet. 2006, 7, 606-619. [CrossRef]

3. Leevers, S.J.; Vanhaesebroeck, B.; Waterfield, M.D. Signalling through phosphoinositide 3-kinases: The lipids take centre stage. Curr. Opin. Cell Biol. 1999, 11, 219-225. [CrossRef]

4. Vivanco, I.; Sawyers, C.L. The phosphatidylinositol 3-Kinase AKT pathway in human cancer. Nat. Rev. Cancer 2002, 2, 489-501. [CrossRef] [PubMed]

5. Cantley, L.C. The phosphoinositide 3-kinase pathway. Science 2002, 296, 1655-1657. [CrossRef]

6. Crowder, R.J.; Phommaly, C.; Tao, Y.; Hoog, J.; Luo, J.; Perou, C.M.; Parker, J.S.; Miller, M.A.; Huntsman, D.G.; Lin, L.; et al. PIK3CA and PIK3CB inhibition produce synthetic lethality when combined with estrogen deprivation in estrogen receptor-positive breast cancer. Cancer Res. 2009, 69, 3955-3962. [CrossRef] [PubMed]

7. Sanchez, C.G.; Ma, C.X.; Crowder, R.J.; Guintoli, T.; Phommaly, C.; Gao, F.; Lin, L.; Ellis, M.J. Preclinical modeling of combined phosphatidylinositol-3-kinase inhibition with endocrine therapy for estrogen receptor-positive breast cancer. Breast Cancer Res. 2011, 13, 1-17. [CrossRef]

8. Sansal, I.; Sellers, W.R. The biology and clinical relevance of the PTEN tumor suppressor pathway. J. Clin. Oncol. 2004, 22, 2954-2963. [CrossRef]

9. Isakoff, S.J.; Engelman, J.A.; Irie, H.Y.; Luo, J.; Brachmann, S.M.; Pearline, R.V.; Cantley, L.C.; Brugge, J.S. Breast cancer-associated PIK3CA mutations are oncogenic in mammary epithelial cells. Cancer Res. 2005, 65, 10992-101000. [CrossRef] [PubMed]

10. Zhao, J.J.; Liu, Z.; Wang, L.; Shin, E.; Loda, M.F.; Roberts, T.M. The oncogenic properties of mutant p110alpha and p110beta phosphatidylinositol 3-kinases in human mammary epithelial cells. Proc. Natl. Acad. Sci. USA 2005, 102, 18443-18448. [CrossRef]

11. Zhang, H.; Liu, G.; Dziubinski, M.; Yang, Z.; Ethier, S.P.; Wu, G. Comprehensive analysis of oncogenic effects of PIK3CA mutations in human mammary epithelial cells. Breast Cancer Res. Treat. 2008, 112, 217-227. [CrossRef]

12. Stemke-Hale, K.; Gonzalez-Angulo, A.M.; Lluch, A.; Neve, R.M.; Kuo, W.L.; Davies, M.; Carey, M.; Hu, Z.; Guan, Y.; Sahin, A.; et al. An integrative genomic and proteomic analysis of PIK3CA, PTEN, and AKT mutations in breast cancer. Cancer Res. 2008, 68, 6084-6091. [CrossRef] [PubMed]

13. Loibl, S.; de la Pena, L.; Nekljudova, V.; Zardavas, D.; Michiels, S.; Denkert, C.; Rezai, M.; Bermejo, B.; Untch, M.; Lee, S.C.; et al. Neoadjuvant buparlisib plus trastuzumab and paclitaxel for women with HER2+ primary breast cancer: A randomised, doubleblind, placebo-controlled phase II trial (NeoPHOEBE). Eur. J. Cancer 2017, 85, 133-145. [CrossRef] [PubMed]

14. Metzger Filho, O.; Goel, S.; Barry, W.T.; Hamilton, E.P.; Tolaney, S.M.; Yardley, D.A.; Rees, R.; Demeo, M.; Mills, C.; Hafner, M.; et al. A mouse-human phase I co-clinical trial of taselisib in combination with TDM1 in advanced HER2-positive breast cancer (MBC). J. Clin. Oncol. 2017, 35, 1030. [CrossRef]

15. Jain, S.; Shah, A.N.; Santa-Maria, C.A.; Siziopikou, K.; Rademaker, A.; Helenowski, I.; Cristofanilli, M.; Gradishar, W.J. Phase I study of alpelisib (BYL-719) and trastuzumab emtansine (T-DM1) in HER2-positive metastatic breast cancer (MBC) after trastuzumab and taxane therapy. Breast Cancer Res. Treat. 2018, 171, 371-381. [CrossRef] [PubMed]

16. Juric, D.; Janku, F.; Rodón, J.; Burris, H.A.; Mayer, I.A.; Schuler, M.; Seggewiss-Bernhardt, R.; Gil-Martin, M.; Middleton, M.R.; Baselga, J.; et al. Alpelisib Plus Fulvestrant in PIK3CA-Altered and PIK3CA-Wild-Type Estrogen Receptor-Positive Advanced Breast Cancer: A Phase 1b Clinical Trial. JAMA Oncol. 2019, 5, e184475. [CrossRef]

17. André, F.; Ciruelos, E.M.; Juric, D.; Loibl, S.; Campone, M.; Mayer, I.A.; Rubovszky, G.; Yamashita, T.; Kaufman, B.; Lu, Y.S.; et al. Alpelisib plus fulvestrant for PIK3CA-mutated, hormone receptor-positive, human epidermal growth factor receptor-2-negative advanced breast cancer: Final overall survival results from SOLAR-1. Ann. Oncol. 2021, 32, 208-217. [CrossRef]

18. Saura, C.; Hlauschek, D.; Oliveira, M.; Zardavas, D.; Jallitsch-Halper, A.; de la Peña, L.; Nuciforo, P.; Ballestrero, A.; Dubsky, P.; Lombard, J.M.; et al. Neoadjuvant letrozole plus taselisib versus letrozole plus placebo in postmenopausal women with oestrogen receptor-positive, HER2-negative, early-stage breast cancer (LORELEI): A multicentre, randomised, double-blind, placebo-controlled, phase 2 trial. Lancet Oncol. 2019, 20, 1226-1238. [CrossRef]

19. Garrido-Castro, A.C.; Saura, C.; Barroso-Sousa, R.; Guo, H.; Ciruelos, E.; Bermejo, B.; Gavilá, J.; Serra, V.; Prat, A.; Paré, L.; et al. Phase 2 study of buparlisib (BKM120), a pan-class I PI3K inhibitor, in patients with metastatic triple-negative breast cancer. Breast Cancer Res. 2020, 22, 120. [CrossRef]

20. Lehmann, B.D.; Abramson, V.G.; Sanders, M.E.; Mayer, E.L.; Haddad, T.C.; Nanda, R.; Van Poznak, C.; Storniolo, A.M.; Nangia, J.R.; Gonzalez-Ericsson, P.I.; et al. TBCRC 032 IB/II Multicenter Study: Molecular Insights to AR Antagonist and PI3K Inhibitor Efficacy in Patients with AR(+) Metastatic Triple-Negative Breast Cancer. Clin. Cancer Res. 2020, 26, 2111-2123. [CrossRef]

21. Martín, M.; Chan, A.; Dirix, L.; O'Shaughnessy, J.; Hegg, R.; Manikhas, A.; Shtivelband, M.; Krivorotko, P.; Lopez, N.B.; Campone, M.; et al. A randomized adaptive phase II/III study of buparlisib, a pan-class I PI3K inhibitor, combined with paclitaxel for the treatment of HER2- advanced breast cancer (BELLE-4). Ann. Oncol. 2017, 28, 313-320. [CrossRef]

22. Burger, M.T.; Pecchi, S.; Wagman, A.; Ni, Z.J.; Knapp, M.; Hendrickson, T.; Atallah, G.; Pfister, K.; Zhang, Y.; Bartulis, S.; et al. Identification of NVP-BKM120 as a Potent, Selective, Orally Bioavailable Class I PI3 Kinase Inhibitor for Treating Cancer. ACS Med. Chem. Lett. 2011, 2, 774-779. [CrossRef] [PubMed] 
23. Ando, Y.; Inada-Inoue, M.; Mitsuma, A.; Yoshino, T.; Ohtsu, A.; Suenaga, N.; Sato, M.; Kakizume, T.; Robson, M.; Quadt, C.; et al. Phase I dose-escalation study of buparlisib (BKM120), an oral pan-class I PI3K inhibitor, in Japanese patients with advanced solid tumors. Cancer Sci. 2014, 105, 347-353. [CrossRef]

24. Bendell, J.C.; Rodon, J.; Burris, H.A.; De Jonge, M.; Verweij, J.; Birle, D.; Demanse, D.; De Buck, S.S.; Ru, Q.C.; Peters, M.; et al. Phase I, dose-escalation study of BKM120, an oral pan-Class I PI3K inhibitor, in patients with advanced solid tumors. J. Clin. Oncol. 2012, 30, 282-290. [CrossRef] [PubMed]

25. Rodon, J.; Braña, I.; Siu, L.L.; De Jonge, M.J.; Homji, N.; Mills, D.; Di Tomaso, E.; Sarr, C.; Trandafir, L.; Massacesi, C.; et al. Phase I dose-escalation and -expansion study of buparlisib (BKM120), an oral pan-Class I PI3K inhibitor, in patients with advanced solid tumors. Investig. N. Drugs 2014, 32, 670-681. [CrossRef]

26. Mayer, I.A.; Abramson, V.G.; Isakoff, S.J.; Forero, A.; Balko, J.M.; Kuba, M.G.; Sanders, M.E.; Yap, J.T.; Van den Abbeele, A.D.; Li, Y.; et al. Stand up to cancer phase $\mathrm{Ib}$ study of pan-phosphoinositide-3-kinase inhibitor buparlisib with letrozole in estrogen receptor-positive/human epidermal growth factor receptor 2-negative metastatic breast cancer. J. Clin. Oncol. 2014, 32, 1202-1209. [CrossRef]

27. Baselga, J.; Im, S.A.; Iwata, H.; Cortés, J.; De Laurentiis, M.; Jiang, Z.; Arteaga, C.L.; Jonat, W.; Clemons, M.; Ito, Y.; et al. Buparlisib plus fulvestrant versus placebo plus fulvestrant in postmenopausal, hormone receptor-positive, HER2-negative, advanced breast cancer (BELLE-2): A randomised, double-blind, placebo-controlled, phase 3 trial. Lancet Oncol. 2017, 18, 904-916. [CrossRef]

28. Di Leo, A.; Johnston, S.; Lee, K.S.; Ciruelos, E.; Lønning, P.E.; Janni, W.; O’Regan, R.; Mouret-Reynier, M.A.; Kalev, D.; Egle, D.; et al. Buparlisib plus fulvestrant in postmenopausal women with hormone-receptor-positive, HER2-negative, advanced breast cancer progressing on or after mTOR inhibition (BELLE-3): A randomised, double-blind, placebo-controlled, phase 3 trial. Lancet Oncol. 2018, 19, 87-100. [CrossRef]

29. Lu, Y.S.; Lee, K.S.; Chao, T.Y.; Tseng, L.M.; Chitapanarux, I.; Chen, S.C.; Liu, C.T.; Sohn, J.; Kim, J.H.; Chang, Y.C.; et al. A Phase Ib Study of Alpelisib or Buparlisib Combined with Tamoxifen Plus Goserelin in Premenopausal Women with HR-Positive HER2-Negative Advanced Breast Cancer. Clin. Cancer Res. 2021, 27, 408-417. [CrossRef] [PubMed]

30. Tolaney, S.M.; Im, Y.H.; Calvo, E.; Lu, Y.S.; Hamilton, E.; Forero-Torres, A.; Bachelot, T.; Maur, M.; Fasolo, A.; Tiedt, R.; et al. Phase Ib Study of Ribociclib plus Fulvestrant and Ribociclib plus Fulvestrant plus PI3K Inhibitor (Alpelisib or Buparlisib) for HR(+) Advanced Breast Cancer. Clin. Cancer Res. 2021, 27, 418-428. [CrossRef]

31. Ndubaku, C.O.; Heffron, T.P.; Staben, S.T.; Baumgardner, M.; Blaquiere, N.; Bradley, E.; Bull, R.; Do, S.; Dotson, J.; Dudley, D.; et al. Discovery of 2-\{3-[2-(1-isopropyl-3-methyl-1H-1,2-4-triazol-5-yl)-5,6-dihydrobenzo[f]imidazo[1,2-d][1,4]oxazepin-9yl]-1H-pyrazol-1-yl\}-2-methylpropanamide (GDC-0032): A $\beta$-sparing phosphoinositide 3-kinase inhibitor with high unbound exposure and robust in vivo antitumor activity. J. Med. Chem. 2013, 56, 4597-4610. [PubMed]

32. Heffron, T.P.; Heald, R.A.; Ndubaku, C.; Wei, B.; Augistin, M.; Do, S.; Edgar, K.; Eigenbrot, C.; Friedman, L.; Gancia, E.; et al. The Rational Design of Selective Benzoxazepin Inhibitors of the $\alpha$-Isoform of Phosphoinositide 3-Kinase Culminating in the Identification of (S)-2-((2-(1-Isopropyl-1H-1,2,4-triazol-5-yl)-5,6-dihydrobenzo[f]imidazo[1,2-d][1,4]oxazepin-9-yl)oxy)propanamide (GDC-0326). J. Med. Chem. 2016, 59, 985-1002. [PubMed]

33. Hoeflich, K.P.; Guan, J.; Edgar, K.A.; O’Brien, C.; Savage, H.; Wilson, T.R.; Neve, R.M.; Friedman, L.S.; Wallin, J.J. The PI3K inhibitor taselisib overcomes letrozole resistance in a breast cancer model expressing aromatase. Genes. Cancer 2016, 7 , 73-85. [CrossRef]

34. Dickler, M.N.; Saura, C.; Richards, D.A.; Krop, I.E.; Cervantes, A.; Bedard, P.L.; Patel, M.R.; Pusztai, L.; Oliveira, M.; Cardenas, A.K.; et al. Phase II Study of Taselisib (GDC-0032) in Combination with Fulvestrant in Patients with HER2-Negative, Hormone Receptor-Positive Advanced Breast Cancer. Clin. Cancer Res. 2018, 24, 4380-4387. [CrossRef] [PubMed]

35. Baselga, J.; Dent, S.F.; Cortés, J.; Im, Y.H.; Diéras, V.; Harbeck, N.; Krop, I.E.; Verma, S.; Wilson, T.R.; Jin, H.; et al. Phase III study of taselisib (GDC-0032) + fulvestrant (FULV) v FULV in patients (pts) with estrogen receptor (ER)-positive, PIK3CA-mutant (MUT), locally advanced or metastatic breast cancer (MBC): Primary analysis from SANDPIPER. J. Clin. Oncol. 2018, 36 (Suppl. 18), LBA1006. [CrossRef]

36. Dent, S.; Cortés, J.; Im, Y.H.; Diéras, V.; Harbeck, N.; Krop, I.E.; Wilson, T.R.; Cui, N.; Schimmoller, F.; Hsu, J.Y.; et al. Phase III randomized study of taselisib or placebo with fulvestrant in estrogen receptor-positive, PIK3CA-mutant, HER2-negative, advanced breast cancer: The SANDPIPER trial. Ann. Oncol. 2021, 32, 197-207. [CrossRef]

37. Pascual, J.; Lim, J.S.; Macpherson, I.R.; Armstrong, A.C.; Ring, A.; Okines, A.F.; Cutts, R.J.; Herrera-Abreu, M.T.; Garcia-Murillas, I.; Pearson, A.; et al. Triplet Therapy with Palbociclib, Taselisib, and Fulvestrant in PIK3CA-Mutant Breast Cancer and Doublet Palbociclib and Taselisib in Pathway-Mutant Solid Cancers. Cancer Discov. 2021, 11, 92-107. [CrossRef]

38. Jhaveri, K.; Chang, M.T.; Juric, D.; Saura, C.; Gambardella, V.; Melnyk, A.; Patel, M.R.; Ribrag, V.; Ma, C.X.; Aljumaily, R.; et al. Phase I Basket Study of Taselisib, an Isoform-Selective PI3K Inhibitor, in Patients with PIK3CA-Mutant Cancers. Clin. Cancer Res. 2021, 27, 447-459. [CrossRef]

39. Fritsch, C.; Huang, A.; Chatenay-Rivauday, C.; Schnell, C.; Reddy, A.; Liu, M.; Kauffmann, A.; Guthy, D.; Erdmann, D.; De Pover, A.; et al. Characterization of the novel and specific PI3K $\alpha$ inhibitor NVP-BYL719 and development of the patient stratification strategy for clinical trials. Mol. Cancer Ther. 2014, 13, 1117-1129. [CrossRef]

40. Bosch, A.; Li, Z.; Bergamaschi, A.; Ellis, H.; Toska, E.; Prat, A.; Tao, J.J.; Spratt, D.E.; Viola-Villegas, N.T.; Castel, P.; et al. PI3K inhibition results in enhanced estrogen receptor function and dependence in hormone receptor-positive breast cancer. Sci. Transl. Med. 2015, 7, 283ra51. [CrossRef] 
41. Mayer, I.A.; Abramson, V.G.; Formisano, L.; Balko, J.M.; Estrada, M.V.; Sanders, M.E.; Juric, D.; Solit, D.; Berger, M.F.; Won, H.H.; et al. A Phase Ib Study of Alpelisib (BYL719), a PI3K $\alpha$-Specific Inhibitor, with Letrozole in ER+/HER2- Metastatic Breast Cancer. Clin. Cancer Res. 2017, 23, 26-34. [CrossRef] [PubMed]

42. André, F.; Ciruelos, E.; Rubovszky, G.; Campone, M.; Loibl, S.; Rugo, H.S.; Iwata, H.; Conte, P.; Mayer, I.A.; Kaufman, B.; et al. Alpelisib for PIK3CA-Mutated, Hormone Receptor-Positive Advanced Breast Cancer. N. Engl. J. Med. 2019, 380, $1929-1940$. [CrossRef] [PubMed]

43. Narayan, P.; Prowell, T.M.; Gao, J.J.; Fernandes, L.L.; Li, E.; Jiang, X.; Qiu, J.; Fan, J.; Song, P.; Yu, J.; et al. FDA Approval Summary: Alpelisib Plus Fulvestrant for Patients with HR-positive, HER2-negative, PIK3CA-mutated, Advanced or Metastatic Breast Cancer. Clin. Cancer Res. 2021, 27, 1842-1849. [CrossRef] [PubMed]

44. Batalini, F.; Moulder, S.L.; Winer, E.P.; Rugo, H.S.; Lin, N.U.; Wulf, G.M. Response of Brain Metastases From PIK3CA-Mutant Breast Cancer to Alpelisib. JCO Precis. Oncol. 2020, 4, 572-578. [CrossRef]

45. Rugo, H.S.; Lerebours, F.; Ciruelos, E.; Drullinsky, P.; Ruiz-Borrego, M.; Neven, P.; Park, Y.H.; Prat, A.; Bachelot, T.; Juric, D.; et al. Alpelisib plus fulvestrant in PIK3CA-mutated, hormone receptor-positive advanced breast cancer after a CDK4/6 inhibitor (BYLieve): One cohort of a phase 2, multicentre, open-label, non-comparative study. Lancet Oncol. 2021, 22, 489-498. [CrossRef]

46. Mosele, F.; Stefanovska, B.; Lusque, A.; Dien, A.T.; Garberis, I.; Droin, N.; Le Tourneau, C.; Sablin, M.P.; Lacroix, L.; Enrico, D.; et al. Outcome and molecular landscape of patients with PIK3CA-mutated metastatic breast cancer. Ann. Oncol. 2020, 31, 377-386. [CrossRef]

47. Signorovitch, J.; Andre, F.; Wang, R.; Lorenzo, I.; Ridolfi, A.; Park, J.; Fillbrunn, M.; Dua, A.; Rugo, H.S. PIK3CA mutation status and progression-free survival in advanced hormone receptor positive (HR+)/human endocrine receptor negative (HER2-) metastatic breast cancer (mBC): A meta-analysis of published clinical trials. J. Clin. Oncol. 2020, 38 (Suppl. 15), 1069. [CrossRef]

48. Rugo, H.S.; Lerebours, F.; Juric, D.; Turner, N.; Chia, S.; Drullinsky, P.; Prat, A.; Vázquez, R.V.; Akdere, M.; Arce, C.; et al. Abstract PD2-07: Alpelisib + letrozole in patients with PIK3CA-mutated, hormone-receptor positive (HR+), human epidermal growth factor receptor-2-negative (HER2-) advanced breast cancer (ABC) previously treated with a cyclin-dependent kinase $4 / 6$ inhibitor (CDK4/6i) + fulvestrant: BYLieve study results. Cancer Res. 2021, 81 (Suppl. 4), PD2-07. 